\title{
Antecedents of Truck Drivers' Job Satisfaction and Retention Proneness
}

(Accepted for publication in the Journal of Business Logistics)

\author{
Günter Prokl \\ Department of Operations Management \\ Copenhagen Business School \\ Christoph Teller \\ Department of Marketing and Retail Management, Surrey Business School \\ University of Surrey \\ Herbert Kotzab (corresponding author) \\ Institute of Logistics Management \\ University of Bremen \\ Rob Angell \\ Cardiff Business School \\ Cardiff University
}




\title{
Antecedents of Truck Drivers' Job Satisfaction and Retention Proneness
}

\begin{abstract}
The aim of this paper is to (1) explore the antecedents of truck drivers' job satisfaction and (2) identify the impact of financial and non-financial job properties on satisfaction with the job and with one's employer and (3) the drivers' proneness to retaining their jobs. Based on the extant literature, we develop a conceptual model that is tested using survey data for 164 truck drivers. Multiple linear and ordinal logistic regressions were used to estimate the proposed effects. The results reveal that non-financial job properties and satisfaction with one's employer affect job satisfaction statistically significantly. Financial and non-financial job properties affect satisfaction with one's employer whereas the former shows a lower impact compared to the latter. Satisfaction with the job and one's employer impacts retention proneness. The contribution of this paper is to (1) add to the understanding of the factors that predict retention of truck drivers in relationship to job satisfaction and (2) highlight the different roles of financial and non-financial job properties in this specific work context.
\end{abstract}

Keywords: trucking; human resources; job satisfaction; retention; survey 


\section{Antecedents of Truck Drivers' Job Satisfaction and Retention Proneness}

\section{INTRODUCTION}

"On the road again, just can't wait to get on the road again" begins the famous song by Willie Nelson. This is certainly true for roads in the United States (US), where 70\% of all freight is delivered by trucks and 3 million truck drivers move 9.2 billion tons of freight per year (American Truck Association 2014). In Germany, the country's roads are "occupied" daily by more than 2 million trucks serving German manufacturing, retail, and service industries. These trucks provide a transportation volume that equals $€ 60$ billion of transportation costs per year. The stock of truck driving licenses issued in Germany totaled about 20 million in 2015 compared to 14 million in 2006 (Statista 2015). In addition, the German Federal Employment Agency reported that there were approximately 550,000 professional drivers as of mid-2013, making them the largest group of employees within the German logistics industry (Bundesamt für Güterkraftverkehr [BAG] 2014).

For many decades, the labor market for truck drivers has been very volatile, and transportation companies, especially those that offer long-distance haulage, as well as irregular route motor carriers, have always faced very high driver turnover (Richard et al. 1994). For example, Min and Lambert (2002) report turnover rates between 92\% and 103\% for American trucking companies. Recent German surveys (TÜV 2012) reported that more than 90\% of German transportation companies indicated a high truck driver turnover rate. High driver turnover is a costly issue for trucking companies at the global level (Fournier et al. 2012). Suzuki et al. (2009) confirms this for the United States. However, similar findings could not be found for the German market. 
Before the 2008 financial crisis, in Europe, and even before then in other countries, especially in the United States, the transportation industry was suffering from a significant shortage of capable drivers. Due to the age shift in the population, many economies will face a significant shortage of drivers in the near future that Roberts (2014) quantifies as a shortfall of nearly 240,000 drivers by 2014 for the United States. In Germany, where more than a third of the employees in the transportation sector are more than 50 years old, transportation associations, as well as various labor market experts, have repeatedly warned about a "foreseeable disaster" (Walter 2012; Kübler et al. 2015). However, filling the gap will be difficult as the working conditions for drivers are poor (Dylan 2007; Gingold 2008; Mallett 2009). Beilock (2003) even calls land-based transportation with its demanding working conditions "sweatshops on wheels."

Explaining the high turnover rate among drivers as a consequence of the working conditions is appealing, and consequently, paying drivers more may help overcome this situation. Min and Lambert (2002) showed how some U.S. companies tried to reduce driver turnover by increasing truck drivers' salaries. German transportation associations, for instance, urge their corporate members to pay higher salaries and propose wage increases up to double existing driver wages (Walter 2012). However, two decades ago, Richard et al. (1995) found that wages are not the main reason for high driver turnover. The researchers identified a lack of supervisory skills at the dispatcher level as one of the main reasons truck drivers leave a company. This finding has been confirmed by Taylor (1991) and Keller and Ozment (1999).

Other researchers also found other reasons for high driver turnover rates rather than wages. De Croon et al. (2004), for example, combine existing organizational stress theory and job transition theory and investigate the effects of stress at work on truck driver turnover. Suzuki et al. (2009) show that high organizational commitment had a positive effect on truck drivers' 
probability of changing jobs. In a literature review, Suzuki et al. (2009) identify the work environment (e.g., pay, home time, driven miles, job security), recruiting methods, management quality, and driver demographics as key factors for explaining during turnover. Huff (2005) also investigate reasons for turnover and identified less stressful working conditions, better working conditions, dishonest employers, and better benefits, in addition to better pay, as the major reasons truck drivers leave a company.

Overall, we can conclude that truck drivers' jobs and retention are of significant importance for the logistics sector and beyond. Trucking companies face high truck driver turnover rates and, therefore, are searching for adequate retention and hiring strategies. At the same time, the work is demanding and arguably not well paid (Min and Emam 2003).

Taking these notions, it may be appealing to develop a macro-relationship (Coleman 1986) between the work environment, pay and driver turnover or retention in order to explain these effects. However, according to Hedström and Ylikoski (2010), explanations that simply include such macro-relationships - that is, in the present case, (extrinsic) job properties and the driver turnover rate - are unsatisfactory as they do not specify the causal mechanisms to which the properties are related. This means we should not directly relate a situation and a system's outcome but include elements of a "theory of action" that opens a "black box" and theorizes about the process through which individual preferences become collective choices. Thus, the behavior of the system is seen as the emergent consequence of the interdependent actions of individual actors that constitute a system (Coleman 1986). Such an opening of a black box includes purpose and goal directedness; however, as this may not happen at the system level, we examine the individual level, in this case the driver. The purposive actions of the actors involved 
sums up to system-level behavior, but these purposive actions are at the same time shaped by the constraints that result from the system (Hedström and Ylikoski 2010).

This emphasis on detailing mechanisms requires explanations that "refer to individuals, their relationships and their actions in addition to whatever other social properties are relevant" (Hedström and Ylikoski 2010). Following the logic of the so called Coleman boat this also implies an analysis in different steps. In the first step, the structural mechanisms that constrain individuals' actions and shape their desires and beliefs should be investigated. In the second step, action-formation mechanisms link the individuals' beliefs or desires to their actions. The third step is the transformation of these actions into social outcomes, in this case, the extraordinarily high turnover rates. Only when we understand the chain of these mechanisms are we able to make sense of the macro-level relationship (Hedström and Ylikoski 2010).

Therefore, job satisfaction plays a central role in turnover decision models at the microlevel (Dipboye et al. 1994). This is also true for the case of truck drivers, as Schulz et al. (2014) have previously shown. Other scholars have examined reasons for job dissatisfaction (de Croon et al. 2004; Huff 2005; Pereira da Silva et al. 2009; Suzuki et al. 2009) with reference to payment, working conditions, and employer characteristics. According to these findings, a lack of job satisfaction leads to truck driver turnover, stress, and depression. We place job satisfaction at the center of the analysis and see it as the central construct that links situation and outcome. Job satisfaction is the anchor point for the causal mechanism that links the truck drivers' work environment to the resulting pattern of behavior, which, in this example, is expressed in the observable turnover and low retention rates. 
To understand the high turnover issue, human resource managers need to better understand whether and why truck drivers are satisfied or dissatisfied with their jobs and why truck drivers (want to) leave (Gooley and Cooke 2002; Schulz et al. 2014). Identifying the level of job satisfaction in service industries, such as trucking, is particularly important as they rely heavily on the input of human resources (Schneider and Bowen 1993; Suzuki 2007; Bode et al. 2011). Here we also see a gap in the literature. Our review of truck driver turnover indicates that drivers' job satisfaction or better dissatisfaction is understood as a mediator for turnover, but beyond that, job satisfaction often is not included in the analysis, and the related managerial issues are not addressed in sufficient detail (De Croon et al. 2004).

Consequently, the aim of this paper is to (1) explore the antecedents of truck drivers' job satisfaction and (2) identify the impact of financial and non-financial job properties on job satisfaction and satisfaction with one's employer and (3) in turn retention proneness. The contribution of this paper is to add to the understanding of what establishes truck drivers' job satisfaction. Our practical contribution is to point human resource managers toward tools that should be employed to increase job satisfaction and, thus, retain truck drivers.

The organization of this article is as follows: First, we provide an overview of the literature related to individual job satisfaction in general. Next, we enlarge on the literature specific to the transportation sector. Both feed into how we theorize and set up our research hypotheses and conceptual model. After we describe and justify the methodology for our empirical study and analysis, we present our results. We subsequently compare our results with findings from the literature and present the main implications for theory and practice. Based on a critical discussion of the limitations of this study, we conclude with suggestions for further research. 


\section{THEORETICAL FOUNDATIONS OF JOB SATISFACTION RESEARCH}

Job satisfaction (its causes and its consequences) has been of interest to researchers for many decades (Mertel 2006). One of the most puzzling questions is related to the specific antecedents of job satisfaction, knowledge of which would provide potential managerial levers for improving staff performance and turnover rates. The literature indicates that the construct of job satisfaction represents an attitude about one's job that is influenced by numerous factors (Lawler 1973; Ilies et al. 2009). A considerable number of definitions, models, and theories exist, all having different research objects and research designs. Mertel (2006) distinguishes between content theories proposed by Maslow (1954), Herzberg et al. (1959), and Alderfer (1972) and process theories put forward by Vroom (1964), Bruggemann et al. (1975), and Locke (1969).

In contrast to Fordism and Taylorism, which essentially see humans as resources who should be managed like machines, the human relations approach (Roethlisberger and Dickson 1939; Mayo 1945) shows that productivity is not exclusively influenced by technical or organizational working conditions. Instead, job satisfaction is considered the result of the social environment within the workplace. The two major types of aspects that determine the social environment and, thus, job satisfaction are, first, the social relations of the working group in which the worker is involved (comprising factors such as group behavior or informal communication) and second, the social conditions developed by the company in which the worker is employed. These aspects provide different perspectives on the way people interrelate, as discussed by McGregor (1960), and on the different management styles that recognize participation and the development of human capital.

Lawler (1973) offers a theory that explains job satisfaction as a result of the discrepancy between expected and perceived rewards in the workplace. In other words, he bases job 
satisfaction on personal determinants and on the job characteristics workers "calculate" are acceptable according to their subjective expectations of a fair reward for their work. Rewards that meet expectations drive job satisfaction. Rewards that are lower than expectations cause dissatisfaction. Rewards that are higher than expectations may cause feelings of guilt or discomfort. Examples of personal determinants include capabilities, skills, experiences, efforts, age, training, education, loyalty, and performance. Job characteristics may include hierarchical level, job severity, independence, self-determination, or responsibility. The theory thus links the development of job satisfaction to the worker's personal properties and job characteristics.

The job characteristics model presented by Hackman and Oldham (1976) focuses on the core job characteristics, that is, skill variety, task identity, task significance, autonomy, and feedback, that are seen as inherent in all jobs. The model is considered one of the most influential in the organizational literature (Behson et al. 2000) and proposes that the relationship between job characteristics and work outcomes is moderated by an employee's desire to obtain growth or personal development and satisfaction from his or her work: an employee's "Growth Need Strength" (GNS). When individuals' GNSs match the job scope or job characteristics, higher performance and satisfaction will result (Hackman and Oldham 1976).

Another important contribution to understanding the causes of individuals' satisfaction and motivation is the two-factor theory proposed by Herzberg (1966), whose key message is that job satisfaction and dissatisfaction are not two extremes on a single dimension and are not driven by the same factors. Instead, satisfaction is driven by a different set of factors from dissatisfaction. The drivers of job satisfaction are called motivators. They arise from the conditions of the job itself. Not having enough motivators does not result in dissatisfaction, just a lower degree of satisfaction. Typical forms of motivators are achievement, recognition, the work 
itself, responsibility, advancement, and growth. The drivers of dissatisfaction are called hygiene factors. They are needed to ensure that employees are not dissatisfied with their work. Improving hygiene factors, however, only decreases dissatisfaction and does not lead to job satisfaction. They arise from the working conditions and cover aspects such as company policy and administration, supervision, relationship with one's superior, working conditions, salary, relationships with one's peers, personal life, relationships with subordinates, status, and security. Thus, hygiene factors address deficits while motivators address expansion.

In Karasek's job demand-control-support (JDCS) model, three dimensions (or constructs) explain the development of stress for the individual at work, and they highlight situational predictors of job satisfaction (Karasek 1979; Karasek and Theorell 1990). According to this model, job satisfaction is associated with the matching of job demands to job control and social support from colleagues. For example, situations in which high job demands are matched to high job control may trigger increased learning, motivation, and development of skills (Karasek and Theorell 1990). Job demands, as an independent variable, measure stressors in the work environment, such as the workload or responsibilities placed on an individual (too high causes stress, too low causes distress). Control and autonomy refer to control of job duties and how an individual is allowed to prioritize duties and decide how to go about completing them. Support addresses the level and type of assistance given by management or a supervisor. Cohrs et al. (2006) criticize — with reference to Herzberg's approach — that the JDCS model points mainly to the deficits of coping with job demands and requirements and thus is based on the absence of dissatisfaction instead of the presence of satisfaction. For that reason, the researchers include additional factors that clearly refer to positive situational characteristics: qualification possibilities and participatory leadership. 
From the management point of view, the question is how to achieve job satisfaction. Cohrs et al. (2006) describe job satisfaction as a result of workers' disposition and situational characteristics. The researchers then separate workers' disposition further into employees' general disposition and work-related disposition. The former is determined individually by the so-called Big Five characteristics: neuroticism, extraversion, openness to experience, agreeableness, and conscientiousness. The latter is determined by occupational self-efficacy, work centrality, and mastery of goals.

Another corresponding and more typical categorization of job satisfaction is the separation of the construct into intrinsic and extrinsic elements. Intrinsic means that the source of job satisfaction comes from within the individual person-placing some kind of psychological value on the person (Richard et al. 1994). The two groups that refer to workers' dispositions in Cohrs et al.'s (2006) categorization may be seen as intrinsic elements. In contrast, extrinsic sources describe the external situation and originate from the outside. They are not within the control of the individual but within the control of management.

Overall, job satisfaction is characterized as "the pleasurable emotional state resulting from the appraisal of one's job as achieving or facilitating the achievement of one's job values" (Locke 1969, 316). Basically, job satisfaction shows how an employee feels about his or her job (Autry and Daugherty 2003). As Locke (1969) further explains, job satisfaction and dissatisfaction stem from the relationship between what an employee wants from the job and how he or she perceives what it offers. Judge et al. (2001a, 2001b) further present the facets of job satisfaction, including pay, promotions, coworkers, supervision, the work itself, recognition, working conditions, the company, and its management, as important drivers of job satisfaction. 
From these different theoretical underpinnings of job satisfaction, we can conclude that job satisfaction — in general—is determined by external and individual factors and results in behavioral outcomes in terms of performance and retention.

\section{CONCEPTUAL MODEL}

\section{Job satisfaction and job properties}

Following Lawler (1973), the antecedents of job satisfaction can be distinguished into intrinsic and extrinsic antecedents. These antecedents differ in terms of — besides other things—whether and how they can be influenced by management and whether and how they subsequently affect the satisfaction level. Richard et al. (1994) suggest the following three reasons for concentrating on factors that can be influenced by management: (1) Organizations have almost no control over the determinants of intrinsic satisfaction. (2) As intrinsic satisfaction is self-administered, different employees are likely to derive satisfaction from very different sources. (3) In direct relation to the second aspect, there is usually no way to influence individual employees. Therefore, companies need to take a macro-perspective and address job satisfaction on an aggregate level.

For the purpose of this article, we follow Richard et al.'s (1994) arguments and focus on the antecedents of job satisfaction that management is able to influence. However, for theorizing, we have to augment this viewpoint. Job satisfaction, which is at the center of the analysis, is seen in this article as the central construct on the micro-level that links job properties and the related outcome, that is, high turnover on the macro-level. Job satisfaction is the anchor point for a causal mechanism that links truck drivers' work environment to the resulting pattern of behavior expressed in an outcome, the observable turnover. We also distinguish between financial and 
non-financial job properties. The significant importance of both types of job properties is grounded in the principal ideas of Maslow (1954) and Alderfer (1972), who distinguish between different human needs that ought to be satisfied. Some are basic needs (e.g., security) and others more superior (e.g., recognition).

Financial job properties, such as the payment of financial benefits, satisfy basic needs. They include salaries, considered one of the most important extrinsic factors determining overall job satisfaction (Porter and Lawler 1968; Ronan and Organt 1973). The influence of satisfaction with financial job properties on the level of overall job satisfaction was found to be positive by McElroy et al. (1993) in tests carried out among truck drivers. Garver et al. (2008) tested pay, equipment, relationship with senior management, and relationship with dispatchers as potential drivers of the intention of a truck driver to stay with a firm and found pay plays a major role in determining truck drivers' intention to stay. Beilock (2003) also identify a significant relationship between financial job properties and job satisfaction linked with willingness to stay in the industry for a longer period of time. Thus, our first hypothesis is as follows:

$\mathrm{H}_{1}$ : The greater the satisfaction with financial job properties, the greater the overall job satisfaction.

Referring to the theoretical principle that explains job satisfaction on the individual level and despite the notion of practitioners, we follow Richard et al. (1994) and do not view financial job properties as the prime suspect for explaining job satisfaction. Edwards et al. (2008) point out that it is not the level of the salary that makes a worker satisfied or unsatisfied with a job; it is the salary's equity or inequity relative to the delivered performance. This view is in line with the theoretical principles (e.g., Lawler 1973; Hackman and Oldham 1976) that contain elements of 
"calculation" or a comparison of expectations with apparent reality. Such structural mechanisms of comparisons need benchmarks and the context of the specific work group environment. In other words, an individual's expectations are determined by the Big Five characteristics (Cohrs et al. 2006), but the expectations are not developed in isolation. Instead, the individuals are typically oriented toward each other, and relations to others, which are in similar situations, are central. In the present case, the workers are in a work environment that is primarily located outside the employer's domain and influence. Truck drivers' reference points are not colleagues within the same company but mostly other drivers met at truck stops or logistics personnel on the loading ramps of different companies. The discussions among these groups may be seen as constraints, and this environment shapes workers' desires and beliefs (Hedström and Ylikoski 2010).

We propose that salaries provide a limited basis for comparisons as they are potentially similarly low for all drivers and additionally regulated by unions. A current CCJ Driver survey reports that many truck drivers in the United States feel inadequately paid and still face the situation of being "on the road again" (Roberts 2014). In general, there is some indication that the possibility of promotion in the near future has a positive impact on job satisfaction (Kosteas 2011). However, for truck drivers there is hardly any opportunity for promotion. There might be some differences regarding allowances or bonuses that might be shared, but we assume that drivers prefer, similar to most people, not to speak openly about their income.

Given this understanding in regards of non-financial properties and its relation to job satisfaction, this leads to the notion that non-financial job properties might play an even more important role in predicting the level of job satisfaction as non-financial properties are easier to observe and to compare. It is easier to observe whether other drivers have more modern trucks or 
are supplied with uniforms, mobile phones, or a corporate credit card for easy fueling. Nonfinancial properties are also means for evaluating and comparing relationships with superiors and management. McElroy et al. (1993) identified the number of working hours and equipment as additional important drivers of truck drivers' job satisfaction. Richard et al. (1994) recognized reward and recognition systems, as well as senior management and attitudes toward dispatchers, as important antecedents of truck drivers' job satisfaction. Williamson et al. (2009) found that job satisfaction was not influenced by illness or injury risk but by work-life conflicts, and Brauckmann and Echterhoff (2008) detected the internal communication style is an antecedent of job satisfaction. One issue for truck drivers can be seen in the relationship between time spent on the road and time spent at home (Roberts 2014). Drickhamer (2007) identified individual recognition as an important issue for job satisfaction in the logistics industry. Thus, we hypothesize that:

$\mathrm{H}_{2}$ : The greater the satisfaction with non-financial job properties, the greater the overall job satisfaction.

In order to further support our argument as to why non-financial job properties might play an even more important role in predicting levels of job satisfaction, we include the following hypothesis:

$\mathrm{H}_{\Delta 12}$ : Non-financial job properties have a stronger positive effect on job satisfaction as compared to financial job properties. 


\section{Job satisfaction vs. employer satisfaction}

In truck drivers' specific work environment, they continuously interact and communicate with other drivers outside their companies. This specific context may provide additional reasons to differentiate job satisfaction as overall job satisfaction and satisfaction with one's current employer. Stephenson and Fox (1996) identified compensation, self-esteem, pride, appreciation, and treatment as important factors that keep truck drivers at a firm. Williams et al. (2011) identified, based on social exchange theory and organizational support theory, different segments of drivers' needs that impact an employee's intent to stay with or leave a company. Again, financial and non-financial criteria play a major role. Their work resulted in a type of Maslow pyramid of the need segments, including primary needs, relationship needs, and careeradvancing needs, that different driver groups have. In line with this idea, several studies have indicated that there is a positive relationship between the financial and non-financial aspects of job satisfaction and satisfaction with one's employer (Beilock 2003; Srivastava 2013; Mahanta 2012). We thus propose the following two hypotheses:

$\mathrm{H}_{3}$ : The greater the satisfaction with financial job properties, the greater the satisfaction with one's employer.

$\mathrm{H}_{4}$ : The greater the satisfaction with non-financial job properties, the greater the satisfaction with one's employer.

In related literature, satisfaction with one's employer is seen as an important management lever that affects job satisfaction (Saridakis et al. 2013; Richard et al. 1994; Glisson and Durick 1988). Keller and Ozment (1999) propose a retention model in which responsiveness and high levels of sensitivity, meaning that the company shows empathy toward the truck drivers' 
requirements and needs, increase retention rates and, thus, decrease driver turnover rates. Furthermore, Min and Emam (2003) show that longevity with the same company affects the likelihood of driver turnover. This leads to our next hypothesis:

$\mathrm{H}_{5}$ : The greater the satisfaction with one's employer, the greater the overall job satisfaction.

Most of the truck drivers' work relationships happen in the public domain instead of inside the company. Thus, overall, the job properties and the related job expectations that impact overall job satisfaction should be nearly homogeneous for the whole working group of truck drivers. However, truck drivers may compare what they "receive" from their employers in terms of financial rewards and non-financial properties, such as equipment from their employer and what other truck drivers receive from theirs. Differences, even small, may imply a mismatch between expecting and receiving and cause dissatisfaction. Thus, we expect that a lack of satisfaction based on comparisons and disappointments is directed more toward employers than toward the job per se.

\section{Job satisfaction and employer satisfaction and retention}

The mechanisms that cause satisfaction with the job and the employer on the individual level finally transform into overall behavior. The final two hypotheses accordingly link satisfaction with one's job and with one's employer to retention. The first hypothesis refers to a lack of job satisfaction that is generally seen as a factor that influences the behavior of the workforce and, thus, the workforce's performance, dropout rates, absenteeism, and (consequently) the company's costs and performance (Dylan 2007). Therefore, we propose the following 
hypothesis:

$\mathrm{H}_{6}:$ The greater the job satisfaction, the greater the retention proneness.

Next we turn our attention to the role that job satisfaction plays as a mediator leading to enhanced retention proneness, or indeed, in this case, a lack to turnover. There is research that job satisfaction as well as attitude towards an employer are distinct pathways leading to turnover and retention proneness. For instance, in their detailed review, Tett and Meyer (1993) separate a satisfaction-to-commitment mediation model and a commitment-to-satisfaction model from an independent-effects model. It is worth noting that the latter calls for research into how attitudes 'towards the job' versus 'towards the company' combine when making decisions about leaving a company. However, it does not assume any notable causality between either types of attitude, nor does it rule out the possibility of reciprocal influence.

We incorporate this latter view into the study proposing that the satisfaction truck drivers exhibit towards their employer is not only affecting their overall job satisfaction (see $\mathrm{H}_{5}$ above) but is also working at the center of a distinct mechanism which directly impacts their retention proneness (Dougherty et al. 1985, Tett and Meyer 1993, Ritter and Anker 2005, Fournier et al. 2012).

Our key argument is based on the notion that different opportunity costs exist for changing job, when compared with those of simply changing position. Despite changing employer, many, indeed most, of the relevant work relationships will remain (e.g., the same people at the same truck stops). A resistance to change employers (opportunity cost) is expected to be rather different for truck drivers than resistance to changing one's job in other lines of profession. Similar to a professional soccer player, whose switching of teams may be seen as 
little more than perhaps just a change in the color of his jersey, truck drivers will likely change the logo displayed on their truck as well as the company name written on their paycheck. The relevant social contacts and the basic work remain the same. We propose that dissatisfaction with one's employer is seen as a key reason to act and change one's current position while low overall job satisfaction is more likely to cause a desire to, more radically, change profession. Our final hypothesis is:

$\mathrm{H}_{7}$ : The greater the satisfaction with one's employer, the greater the retention proneness.

Beilock and Capelle (1990) identify other, demographic, characteristics, such as drivers' age, drivers' educational level, and union connections, as causal factors for truck driver turnover. We see specific demographic data such as driver's age, work experience, company size, and workload as relevant context factors and include them in our approach as control variables.

To conclude the discussion about the role of financial and non-financial job properties in job and employer satisfaction, as well as retention proneness, Figure 1 illustrates the steps and the conceptual model that underpin the study. 
Figure 1: Conceptual model.

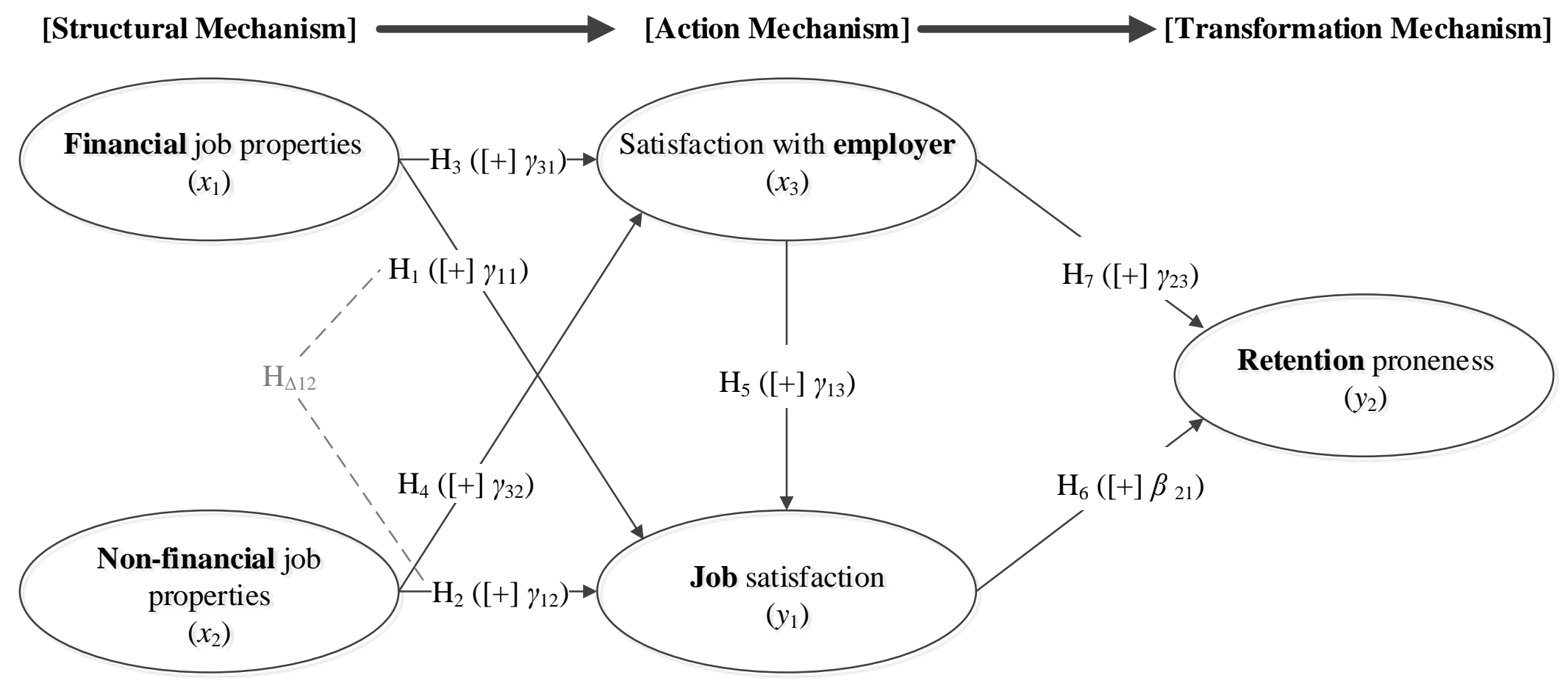




\section{METHODOLOGY}

\section{Research design}

To investigate the drivers of job satisfaction, we conducted a survey in one of the largest European countries and transit hubs, Germany. The survey population consisted of all truck drivers who work for German logistics companies whose general managers agreed to participate in the study and all truck drivers who requested the questionnaire themselves via a provided website or fax. By focusing on truck drivers who work for German logistics companies, we excluded from the sample foreign drivers who travel through Germany in transit traffic and those on cabotage traffic within Germany. A total of 1,058 questionnaires were sent to drivers or contact people who forwarded them to truck drivers. Each questionnaire included a cover letter and instructions on how to complete the questionnaire. To reach all German truck drivers, we promoted the study additionally on radio stations and on flyers that were distributed to public locations frequented by truck drivers. This approach conformed to Dillman et al.'s (2009) tailored design method for self-administered surveys, aimed at ensuring high response rates. A total of 143 completed questionnaires were returned, representing a response rate of $13.5 \%$. To test for non-response errors, we followed the procedure suggested by Wagner and Kemmerling (2010) and compared the variables used in the model estimation (Table 2) between early and late respondents. The $t$-tests did not show significant differences between the two respondent groups $\left(t_{(138)}<1.977\right)$. Furthermore, we differentiated the sample into direct respondents and respondents via company contact and could neither identify significant differences in their answers. We concluded that the data were not affected by non-response errors.

\section{Sample characterization}


Regarding the respondents' personal profiles, the sample included 138 male drivers and only five female drivers (3.5\%). Most drivers (37.1\%) were between 35 and 44 years old, $27.3 \%$ were between 45 and 54 years old, and $18.9 \%$ were between 25 and 34 years old. On average, the drivers in the sample said they had been working as a truck driver for 17.48 years (standard deviation $(\sigma), 10.2)$, which showed a wide span between absolute beginners and those with 44 years of experience. In terms of education, $54.5 \%$ held a general secondary school degree, $30.1 \%$ had attended intermediate secondary school, $4.9 \%$ had attended a specialized grammar school, and the remainder had attended grammar schools, specialized upper schools, or part-time vocational schooling. Only $32.9 \%$ had completed professional driver training, and $81.1 \%$ had worked in a number of very different professions before they had become truck drivers. The average work hours totaled 54.7 hours per week $(\sigma, 11.1): 46.2 \%$ of the drivers indicated that they worked during the day and the night, $35 \%$ worked only during the day, and $18.1 \%$ worked only during the night.

\section{Scales and control variables}

Scale items related to financial and non-financial job properties were adapted from Stephenson and Fox (1996) and Richard et al. (1994). The financial items referred to salaries, hourly wages, allowances, and bonuses while the non-financial items included work time allocation, work environment, work equipment, and the management team, as well as management styles and career development opportunities. The constructs satisfaction with one's employer, job satisfaction, and retention proneness were adapted from Beilock and Capelle (1990), Beilock (2003), Richard et al. (1994), Garver et al. (2008), Autry and Daugherty (2003), and Williams et al. (2011). Based on the results of the pretests conducted among 20 truck drivers, we opted to use 
single items that represented the constructs as global constructs. Furthermore, we consulted the decision guidelines on applying single versus multi-item scales in management research, proposed by Fuchs and Diamantopoulos (2009). According to their guidelines, we could be confident in using a single-item measurement approach for the three dependent constructs because (1) the constructs had a concrete and one-dimensional nature, (2) the primary research objective was to gain a general explorative view of the construct's role within the concept of employment satisfaction and retention, (3) the sample population was diverse, and (4) the sample size was limited, due to the challenge involved in motivating truck drivers to participate in such studies. Consequently, we argue, in line with Hair et al. (2009), that if a construct with only one measure is acceptable, then any related models are acceptable as are any conclusions drawn.

Table 1: Scales, central tendency measures, and local fit measures 


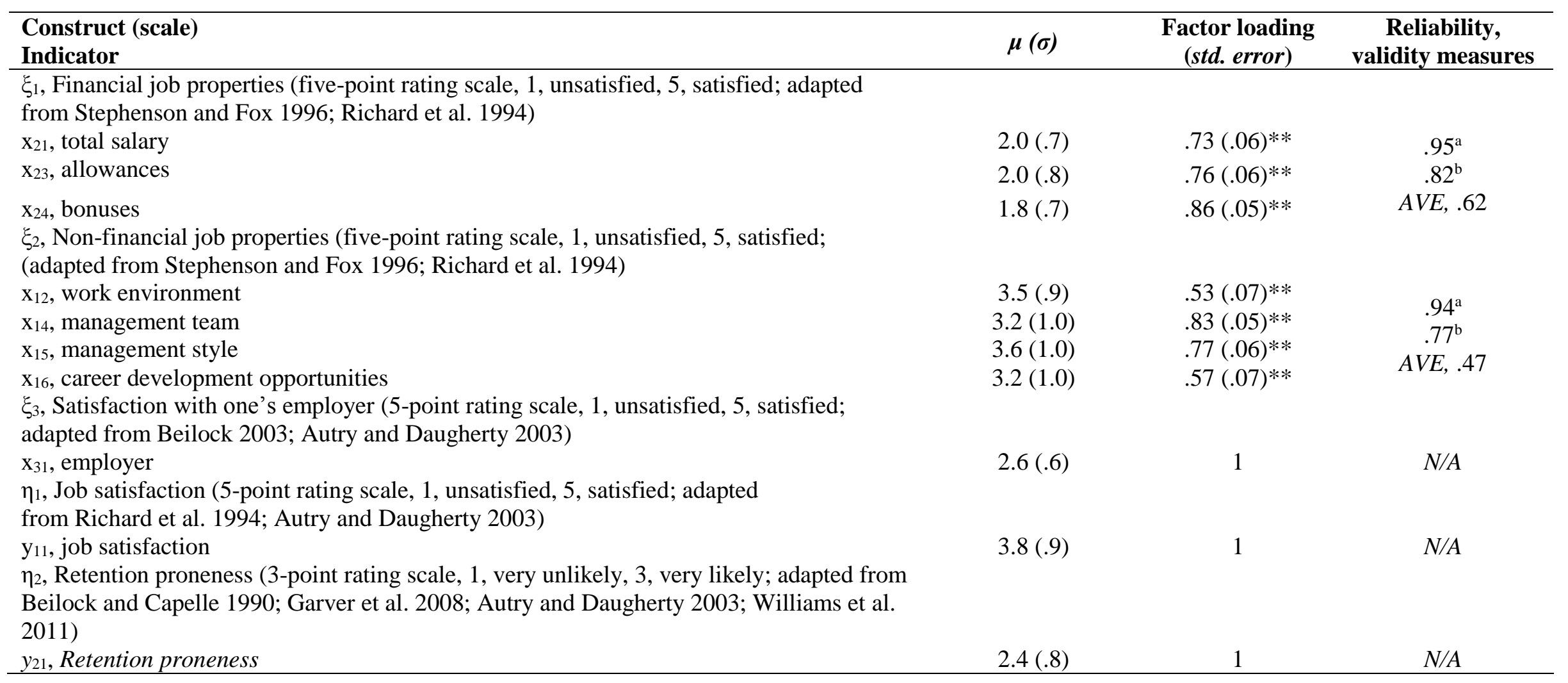

Note: $\mu$, mean value; $\sigma$, standard deviation; ${ }^{a}$ McDonald's omega; ${ }^{b}$ Cronbach alpha; $A V E$, average variance extracted; ${ }^{* *} t<.01$ 
We considered four control variables in the models that might influence the effects hypothesized: age (c1), work experience (c2), workload (c3), and company size (c4); see Figure 1. All four variables capture characteristics that may influence the perception of one's job environment.

\section{Scale validation}

To evaluate the composition of the two scales (financial job properties and non-financial job properties), we specified a confirmatory factor analysis in Mplus 7.0 using robust maximum likelihood estimation (Muthén and Muthén 2012). The two-factor model revealed a good fit to the data (Hu and Bentler 1999): $\chi^{2}=21.91 ; d f .=13 ; p>.05$; comparative fit index (CFI) $=.97$; the Tucker-Lewis index $(\mathrm{TLI})=.95$; root mean square error of approximation $($ RMSEA $)=.07 ;$ standardized root mean square residual $($ SRMR $)=.05$. The standardized coefficients for each factor loading estimate are provided in Table 1. In line with conventional advice in the latent modeling literature (i.e., Bagozzi and Yi 2012), many of the coefficients were greater than the .70 level, and all exceeded the .50 threshold.

Next, we assessed the convergent and discriminant validity and internal consistency of the measurement scales. For convergent validity, we followed Fornell and Larcker's (1981) average variance extracted (AVE). Convergent validity is demonstrated when 50\% (.50) or more of the factor variance is extracted from the observed items. This was satisfied in the case of financial job properties (AVE, .62) but was slightly under the recommended threshold for non-financial job properties (AVE, .47). Given that the difference was marginal, we retained the scale, but we duly noted the failure in this test as a consideration in the inferences we made involving the scale. We assessed discriminant validity by ascertaining that the AVE for both factors was greater than the squared correlation between them $\left(r_{\mathrm{xy}}\right.$, $.41^{2}$ ). Finally, we established the internal consistency of each scale by producing an estimate 
for McDonald's omega (McDonald 1985) — a measure of scale reliability that is more appropriate for congeneric models than the more commonly employed Cronbach alpha coefficient (Revelle and Zingbarg 2009). The estimates for both scales exceeded .70, suggesting a satisfactory degree of internal consistency.

Table 2: Inter-variable correlations

\begin{tabular}{lcccc}
\hline & FJ & NFJ & SE & JS \\
\hline Financial job properties (FJ) & 1 & & & \\
Non-financial job properties (NFJ) & $.37^{* *}$ & 1 & & \\
Satisfaction with one's employer (SE) & $.50^{* *}$ & $.53^{* *}$ & 1 & \\
Job satisfaction (JS) & $.29^{* *}$ & $.58^{* *}$ & $.46^{* *}$ & 1 \\
\hline
\end{tabular}

Note: **, significant at $p<.01 ; *$, significant at $p<.05$

\section{Common method bias}

We used data based on self-reports. Therefore, we considered the issue of common method bias (CMB) and followed a two-step approach: (1) When we were designing the questionnaire, we tried to avoid CMB up front, by considering the notions of Podsakoff et al. (2003, 2012). We did not reveal the specific purpose of the study, and we assured the respondents confidentiality. We clearly separated the questions into different sections, and we applied different scales throughout the questionnaire. (2) We also tested whether common method variance biased the data ex post. We applied Harman's one-factor test (Podsakoff and Organ 1986) and thus conducted an exploratory factor analysis (EFA) on the variables using unrotated principal component factor analysis, constraining the number of factors to be extracted to one, that is, one general factor. We found that the one-factor solution accounted for around one third of the total variance. This result suggests that common method variance is not a significant issue in the data, implying that $\mathrm{CMB}$ will not harm the interpretation of the results. 


\section{HYPOTHESIS TESTING}

\section{Analyses}

After we validated each scale, we estimated structural parameters in line with each hypothesis. This consisted of two multiple linear regression models in we specified satisfaction with one's employer and job satisfaction as dependent variables and an ordinal logistic regression for the retention proneness measure, captured as a categorical variable (see Table 1). All of the remaining analyses were completed in SPSS 20.0.

To enable meaningful comparison of the independent variables in each model, we standardize the measures for financial job properties and non-financial job properties into Zscore units, before we form a composite variable using the standardized score for each scale item. We then standardize both composite variables, as well as satisfaction with one's employer and job satisfaction, with the $Z$-score, where $\mathrm{x}$-mean $=0$ and $\mathrm{s}=1$. We now present each of the three models.

Model 1: job properties $\left(x_{1}, x_{2}\right)$, satisfaction with one's employer $\left(x_{3}\right)$ and job satisfaction $\left(y_{1}\right)$ To test hypotheses 1,2 , and 3, we regressed on variables financial job properties, nonfinancial job properties, and satisfaction with one's employer on job satisfaction. We include the control variables $c_{1}$ through $c_{4}$ as covariates in the model estimation.

Before interpreting the model, we tested whether the requirements for carrying out a multiple-regression analysis were met. We looked for biases in the data in the form of heteroscedasticity and non-linearity by plotting the standardized residuals against the standardized predicted values. Here, we see a random array of dots instead of a funnel of dots and the appearance of any curves in the dots. This suggests the absence of such biases.

Next, we looked at problems related to the correlation between the independent variables in order to detect problems related to multicollinearity. None of the correlations 
between the variables in the models are higher than .6 , and the values of the variance inflation factor (VIF) are well below 4. The tolerance levels are all larger than .20 (Tabachnick and Fidell 2006). We therefore conclude that multicollinearity is not an issue in the present study.

Last, we evaluated the data with reference to potential outlier issues. Two cases had standardized residuals > 3.0 standard deviation $(\mathrm{SD})$ from the mean (Miles and Shevlin 2001). We investigated these two cases using Cook's distance. Neither case revealed any cause for concern as both had a Cook's distance score of $<1.0$. To be conservative, we estimated two models, one including and the other excluding these two cases. As a result, model fit increased from .36 to .46 . Therefore, we choose to report the model in which both cases are excluded. Overall, the regression model is statistically significant $(F=11.85 ; d f=$ $7 ; \operatorname{sig}=.01)$.

Table 3 shows the modeling results that indicate that non-financial job properties and satisfaction with one's employer significantly affect job satisfaction (confirming hypotheses 2 \& 5), whereas financial job properties do not show a statistically significant effect, which leads to the rejection of the first hypothesis. None of the control variables impact the dependent variable statistically significantly. To further test the robustness of our conclusions, we established and confirmed hypotheses $\mathrm{H}_{\Delta 12}$, that non-financial job properties did indeed have a statistically stronger influence (i.e. effect size) on job satisfaction as compared to financial job properties using Cohen et al.'s (2003) procedure $(\mathrm{t}=16.15,1 d f$, $p<.01)$.

Table 3: Estimation results for Model 1

\begin{tabular}{lcccc}
\hline $\begin{array}{l}\text { Dependent variable: Job satisfaction } \\
\left(\boldsymbol{y}_{\mathbf{1}}\right)\end{array}$ & $\boldsymbol{b}$ & SE $\boldsymbol{B}$ & $\boldsymbol{\beta}$ & $\begin{array}{c}\boldsymbol{t} \\
(\boldsymbol{p})\end{array}$ \\
\hline Constant & .043 & .507 & - & $.086(.932)$ \\
$x_{1}$, financial job properties $\left(\mathrm{H}_{1}\right)$ & .012 & .118 & .012 & $.098(.922)$
\end{tabular}




$\begin{array}{lcccc}x_{2} \text {, non-financial job properties }\left(\mathrm{H}_{2}\right) & .447 & .073 & .482 & 6.138(<.001) \\ \begin{array}{l}x_{5}, \text { satisfaction with one's employer } \\ \left(\mathrm{H}_{5}\right)\end{array} & .248 & .074 & .266 & 3.373(.001) \\ c_{1} \text {, age } & -.013 & .080 & -.015 & -.163(.871) \\ c_{2} \text {, work experience } & -.005 & .009 & -.060 & -.525(.525) \\ c_{3} \text {, workload } & -.001 & .006 & -.017 & -.255(.799) \\ c_{4} \text {, company size } & .058 & .036 & .111 & 1.635(.104)\end{array}$

Model 2: job properties $(x 1, x 2)$ and satisfaction with one's employer (x3)

To test hypotheses 3 and 4, we regressed the variables financial job properties and nonfinancial job properties on satisfaction with one's employer. Again, we include the controls as covariates.

When we tested for biases, we did not find issues related to heteroscedasticity, nonlinearity, multicollinearity, or outliers. The regression model is statistically significant at the $.1 \%$ level $(F=11.53 ; d f=6)$. Looking at the overall fit of the model by interpreting the coefficients of determination and the adjusted $r^{2}$ values, we see that the dependent variables account for $38 \%$ of the variation in satisfaction with one's employer.

Table 4 shows the modeling results that indicate that both independent variables, nonfinancial and financial job properties, have statistically significant effects on the dependent variable satisfaction with one's employer.

Table 4: Estimation results for Model 2

\begin{tabular}{lcccc}
\hline $\begin{array}{l}\text { Dependent variable: Satisfaction } \\
\text { with one's employer }\end{array}$ & $\boldsymbol{b}$ & SE $\boldsymbol{B}$ & $\boldsymbol{\beta}$ & $\begin{array}{c}\boldsymbol{t} \\
(\boldsymbol{p})\end{array}$ \\
\hline Constant & .211 & .440 & - & $.479(.633)$ \\
$x_{1}$, financial job properties $\left(\mathrm{H}_{3}\right)$ & .211 & .078 & .211 & $2.689(.008)$ \\
$x_{2}$, non-financial job properties $\left(\mathrm{H}_{4}\right)$ & .457 & .076 & .457 & $6.022(<.001)$ \\
$c_{1}$, age & .008 & .093 & .008 & $.083(.934)$
\end{tabular}




\begin{tabular}{lllll}
$c_{2}$, work experience & -.008 & .010 & -.083 & $-.816(.416)$ \\
$c_{3}$, workload & -.001 & .007 & -.016 & $-.217(.828)$ \\
$c_{4}$, company size & -.004 & .042 & -.007 & $-.090(.928)$ \\
\hline
\end{tabular}

When we once again compare the size of these effects, we see that non-financial job properties have a greater influence on employer satisfaction $(\mathrm{t}=15.79, d f=1, \mathrm{p}<.01)$. The control variables are all statistically non-significant and do not affect the model. Overall, these results confirm hypotheses 3 and 4 .

Model 3: satisfaction with one's employer $\left(x_{3}\right)$, job satisfaction $\left(y_{1}\right)$ and retention proneness $\left(y_{2}\right)$

In the final model estimation, we regressed satisfaction with one's employer and job satisfaction on the retention proneness. The four control variables were included as described. We used an ordinal logistic regression (logit) in SPSS 20.0. This acknowledges the categorical nature of the dependent variable 'retention proneness'.

Again, we found no issues related to heteroscedasticity, non-linearity, multicollinearity, or outliers. When we evaluate the model fit, the log likelihood value is 238.82 , and the $\chi^{2}$ value is $40.29(d f=8, p<.001)$. Thus, we can reject the null hypothesis that all of the predictor variables are equal to zero. The pseudo $r^{2}$ (Nagelkerke) value is .29.

The results in Table 5 reveal significant effects of job satisfaction and satisfaction with one's employer that lead to acceptance of hypotheses 6 and 7. The control variables again show a statistically non-significant impact on the dependent variable.

Table 5: Estimation results for Model 3

\begin{tabular}{llccc}
\hline $\begin{array}{l}\text { Dependent variable: Retention } \\
\text { proneness }\left(y_{2}\right)\end{array}$ & $b$ & SE $B$ & Wald & $\begin{array}{c}p \\
(d f=1)\end{array}$ \\
\hline
\end{tabular}




\begin{tabular}{lcccc}
\hline Threshold [Retention proneness = 1] & -.1729 & 1.100 & 2.468 & .116 \\
$\quad$ [Retention proneness = 2] & -.310 & 1.089 & .081 & .776 \\
$\begin{array}{l}\quad .621 \\
y_{1} \text {, job satisfaction }\left(\mathrm{H}_{6}\right)\end{array}$ & .261 & 5.684 & .017 \\
$\begin{array}{l}x_{5} \text {, satisfaction with one's employer } \\
\left(\mathrm{H}_{7}\right)\end{array}$ & .482 & .218 & 4.898 & .027 \\
$c_{1}$, age & -.237 & .232 & 1.047 & .306 \\
$c_{2}$, work experience & .040 & .025 & 2.499 & .114 \\
$c_{3}$, workload & .006 & .016 & .152 & .696 \\
$c_{4}$, company size & -.085 & .106 & .638 & .424 \\
\hline
\end{tabular}




\section{DISCUSSION AND CONCLUSION}

\section{Theoretical implications}

"Can't buy me love”: The findings show that money cannot buy job satisfaction but may help an employer remain attractive to a truck driver. This major finding of the study presents the paramount importance of non-financial properties for job satisfaction and, in turn, retention proneness. More specifically, the antecedent of job satisfaction subsumes nonfinancial job properties, such as work time allocation, work environment, the management team and style, and career development opportunities. Based on the first model that links the financial and non-financial job properties to job satisfaction, we find that the non-financial components are highly significant while, interestingly enough, the financial properties are not. This result clearly supports Drickhamer's (2007) findings in the truck driver context.

Based on this result, we conclude that financial properties are not the key antecedents of job satisfaction. However, this conclusion is drawn for truck drivers who are already involved in the job. We cannot necessarily conclude that financial job properties are not important for people who choose not to become truck drivers.

\section{Satisfaction with one's employer}

The results are similar for truck drivers' satisfaction with their employer but not identical. In this context, non-financial properties play also a more important role. But one major difference refers to the role of financial properties when it comes to satisfaction with employers. The model shows also a significant relationship between financial job properties and satisfaction with one's employer. We see this as the first indicative support for our theorizing of the proposed action mechanisms that explain driver turnover. Truck drivers direct their comparison between expectations and receipt (see Lawler 1973) less toward the job as such but more toward their employer. They blame the latter for discrepancies that 
potentially implicate action. The only options to act are either to stop driving trucks completely (drop out) or to change one's employer (churning). As the former option is associated with higher opportunity cost, truck drivers rationalize and cope with the unchangeable truth of low salaries. However, this works only as long as the comparison with other truck drivers who are employed by other companies reveals no discrepancies. Or even better when truck drivers feel that their fellow colleagues receive even less. In this regard, the high relevance of non-financial properties may be further explained by comparing opportunities among truck drivers and across companies.

\section{The job versus the employer}

The second indicator is the relationship between satisfaction with one's employer and job satisfaction in general. The results show a statistically significant relationship between satisfaction with one's employer and with one's job. This finding appears in line with the current understanding of this relationship suggested by Saridakis et al. (2013) and Richard et al. (1994).

The finding also supports our view that satisfaction with one's employer is at the core of the individual mechanisms that cause individual drivers' action. Given the very nature of the job of a truck driver, which (unlike other more stationary jobs) involves working at a distance from one's employer's premises, it appears almost paradoxical that the truck drivers refer so much to satisfaction with one's employer.

\section{Satisfaction and retention proneness}

The link between job satisfaction and the proneness to staying in the job turned out to be statistically significant. This result supports de Croon et al.'s (2004) and Periera da Silva et al.'s (2009) notions. Satisfaction with one's employer also has a statistically significant 
impact on retention. Thus, job satisfaction and satisfaction with one's employer are important sources for retention proneness. Due to the applied model and the type of data, we are not able to compare the strength of the impact. However, it appears rational to assume that lack of satisfaction with one's employer is related more to a potential change in one's position (i.e., churning) within the industry while a general lack of job satisfaction may even cause a drop out. However, the latter is associated with higher opportunity cost. Thus, we conclude that different variables and mechanisms lead to job satisfaction and satisfaction with one's employer compared to retention, which is in line with Min and Emam's (2003) findings.

\section{Practical implications}

The results of the study have direct managerial implications. The results provide human resource managers in this specific industry with the necessary insight into which antecedents of satisfaction and, more importantly, retention should be prioritized.

Based on the significant impact of non-financial job properties on job satisfaction in general and satisfaction with one's employer in particular, we propose that the priority for human resource managers must be to improve the non-financial instead financial job properties in order to maintain a high likelihood of retention.

Referring to Hertzberg's (1966) ideas, we also propose human resource managers should concentrate primarily on non-financial properties that are motivators - at least when it comes to the issue of turnover.

It also appears that satisfaction with the job per se and satisfaction with one's employer are based on different individual assessment mechanisms. This finding results in the proposition that a lack of employer satisfaction in combination with the factual low opportunity cost for a truck driver associated with a change in employer builds the basis for the individual action mechanism that finally transforms into the overall pattern of high 
turnover rates. Although the opportunity cost of a position change may be low for truck drivers, the costs typically are high for employers (Fournier et al. 2012; Suzuki et al. 2009). The logical counter-mechanism for an employer should thus be seen in an increase in the opportunity costs for truck drivers (Keller 2002).

Non-financial job properties provide opportunities for the management to create such opportunity cost. Min and Emam (2003) argue that companies with fewer than 50 truck drivers show lower turnover rates than companies with many drivers. Similar relationships are proposed for truck drivers who have more than six years' experience at the same company compared to those who have worked less in the same occupation. As we could not confirm in the models any significant influence of age, work experience, or company size, we assume that associated soft issues, such as increased familiarity in small companies or the loss of a six-year relationship, not structural issues, provide these behavior patterns.

This implies a kind of paradoxical situation for a single company in contrast to the whole trucking industry, which brings to mind the well-known metaphor of the two hikers who meet a Grizzly in the Rocky Mountains. Although the big Grizzly, in this case named turnover, is too strong and too fast to be outpaced by the hikers, it might be very effective for one hiker to put on his running shoes and outrun the other. In this case, this would mean to apply primarily non-financial instruments that would be called motivators in Herzberg's (1966) terminology and thus become, in comparison, a more attractive employer. Based on the results, we assume that even low investments, such as in driver uniforms (and thus identification with the company), mobile phones, or fuel cards for drivers may have an impact but may also wear out over time when these investments become standard across the industry.

\section{Limitations and future research avenues}


This study is not without its limitations, which provide avenues for further research. This research was undertaken in a specific setting, that is, Germany and the logistics industry; thus, any generalizability of the findings to different employment contexts should be treated with caution. However, this study provides the opportunity for the study to be replicated in other countries and industries.

In particular, due to the findings for the financial and non-financial job properties, it could be interesting to compare the findings across different populations of drivers with different geographic and social contexts.

In our understanding, truck drivers in the United States, Germany, and Sweden work in similar work environments with comparable context factors such as working conditions and salary level. Truck drivers in Germany's neighbors such as Denmark or, in particular, Switzerland work under different conditions that include stricter legal protection, union support, and competitive salary levels.

Our study is based on data we retrieved from employed drivers, that is, drivers who were already or still in their job. The related conclusions on retention primarily refer to turnover and less to driver shortages. For research on driver shortages, it might be more enlightening to analyze the attitudes of truck drivers who dropped out of the industry or workers with similar educational levels who might choose to work as a truck driver but have not done thus far.

The results are also limited by the fact that, although the proposed model includes key drivers of job satisfaction, the model does not include all antecedents of the work environment of truck drivers. Exploring other antecedents and potential moderators (e.g., socio-demographics) in the model would provide further clarity and represent a promising extension of the study. 
Finally, this study was quantitative. Qualitative insight through, for example, semistructured interviews with truck drivers and human resource managers would provide a sensible supplement to this research. Therefore, it would be interesting to further investigate and distinguish the non-financial properties that perform well as motivators in comparison to those that are, in Herzberg's (1966) terminology, hygiene factors.

\section{NOTES}

Alongside our use of ordinary least squares (OLS) estimation in the multiple regression analysis, we also estimated each model using partial least squares (PLS) estimation in a structural equation modeling framework. We identified very few differences in the results between the two statistical approaches, but choose to present the results from the former given the rich statistical theory that underpins it as a technique. 


\section{References}

Alderfer, C.P. 1972. Existence, Relatedness, and Growth: Human Needs in Organizational Settings. New York, NY: Free Press.

American Truck Association. 2014. "Reports, Trends \& Statistics." http://www.trucking.org/News_and_Information_Reports_Industry_Data.aspx (accessed 02 May 2015).

Autry, C.W., and Daugherty, P.J. 2003. "Warehouse Operations Employees: Linking PersonOrganization Fit, Job Satisfaction, and Coping Responses.” Journal of Business Logistics $24(1): 171-197$.

Bagozzi, R.P., and Yi, Y. 1988. "On the Evaluation of Structural Equation Models.” Journal of the Academy of Marketing Science 16:74-94.

Behson, S., Eddy, E., and Lorenzet, S. 2000. "The Importance of the Critical Psychological States in the Job Characteristics Model: A Meta-Analytic and Structural Equations Modeling Examination." Current Research in Social Psychology 5 (9):170-189.

Beilock, R. 2003. “The Elusive Sweatshop.” Transportation Quarterly 57 (3):53-165.

Beilock, R., and Capelle, Jr., R.B. 1990. “Occupational Loyalties among Truck Drivers.” Transportation Journal 29 (3):20-28.

Bode, C., Lindemann, E., and Wagner, S. 2011. “The Impact of Delivery Personnel on Customer Purchase Behavior.” Journal of Business Logistics 32 (1):99-114.

Brauckmann, J., and Echterhoff, W. 2008. Die Kommunikation in Speditionen im Jahr 2008. Cologne: TÜV.

Bruggemann, A., Groskurth, P., and Ulich, E. 1975. Arbeitszufriedenheit. Bern: Huber. Bundesamt für Güterkraftverkehr. 2014. Marktbeobachtung Güterverkehr: Auswertung der Arbeitsbedingungen in Güterverkehr und Logistik 2014-I. Cologne: Bundesamt für Güterverkehr. 
Cohen, J., Cohen, P., West, S. G., \& Aiken, L. S. 2003. Applied Multiple

Regression/Correlation Analysis for the Behavioral Sciences (3rd ed.). New York: Routledge.

Cohrs, C., Abele, A., and Dette, D. 2006. "Integrating Situational and Dispositional Determinants of Job Satisfaction: Findings from Three Samples of Professionals.” Journal of Psychology 140 (4):363-395.

Coleman, J. 1986. "Social Theory, Social Research, and a Theory of Action.” American Journal of Sociology 91:1309-1335.

De Croon, E., Sluiter, K., and Blonk, R. 2004. “Stressful Work, Psychological Job Strain, and Turnover: A 2-Year Prospective Cohort Study of Truck Drivers.” Journal of Applied Psychology 89 (3):442-454.

Dillman, D.A., Smyth, J.D., and Christian, L.M. 2009. Internet, Mail, and Mixed-mode Surveys: The Tailored Design Method. Hoboken, NY: John Wiley and Son.

Dipboye, R.L., Smith, C.S., and Howell, W.C. 1994. “Job Attitudes.” In Understanding Industrial and Organizational Psychology, edited by R.L. Dipboye, C.S. Smith, and W. C. Howell , 139-178. Orlando, FL:Harcourt Brace College Publisher.

Dougherty, T.W., Bluedorn, A.C., and Keon, T.L. 1985. "Precursors of employee turnover: A multi-sample causal analysis.” Journal of Occupational Behaviour 6 (2):259-271.

Drickhamer, D. 2007. “Logistically Speaking: Money Can’t Buy Happiness, but It Helps.” http://mhlnews.com/global-supply-chain/logistically-speaking-money-cant-buyhappiness-it-helps (accessed 02 May 2015).

Dylan, G. 2007. "New Drivers Needed - Or the Industry Faces a Crisis." Commercial Motor $206(5245): 28-29$. 
Edwards, B.D., Bell, S.T., Arthur, Jr., W., and Decuir, A.D. 2008. "Relationships between Facets of Job Satisfaction and Task and Contextual Performance." Applied Psychology: An International Review 57 (4):44-465.

Fornell, C., and Larcker, D.F. 1981. "Evaluating Structural Equation Models with Unobservable Variables and Measurement Error." Journal of Marketing Research 18:3940.

Fournier, P., Lamontagne, S., and Gagnon, J. 2012. "Interactions between Dispatchers and Truck Drivers in a High Turnover Context.” Industrial Relations 67 (2):263-282.

Fuchs, C., and Diamantopoulos, A. 2009. “Using Single-Item Measures for Construct Measurement in Management Research.” Die Betriebswirtschaft 69:195-210.

Garver, M.S., Williams, Z., and Taylor, G.S. 2008. "Employing Latent Class Regression Analysis to Examine Logistics Theory: An Application of Truck Driver Retention.” Journal of Business Logistics 29 (2):233-257.

Gingold, S. 2008. "State of the Industry." US Business Review 9 (8):16-17.

Glisson, C., and Durick, M. 1988. "Predictors of Job Satisfaction and Organizational Commitment in Human Service Organizations.” Administrative Science Quarterly 33 (1):61-81.

Gooley, T., and Cooke, J. 2002. “Are Logistics Pros Happy on Their Job?” Logistics Magazine 41 (11):21.

Hackman, J., and Oldham, G. 1976. "Motivation through the Design of Work: Test of a Theory." Organizational Behavior and Human Decision Processes 16 (2):250-279.

Hair, Jr., J.F., Black, W.C., Babin, B.J., and Anderson, R.E. 2009. Multivariate Data Analysis. A Global Perspective. Upper Saddle River, NJ: Pearson.

Hedström, P., and Ylikoski, P. 2010. "Causal Mechanism in the Social Sciences.” Annual Review of Sociology 36:49-67. 
Herzberg, F. 1966. Work and the Nature of Man. Cleveland, OH: World Publishing.

Herzberg, F., Mausner, B., and Snyderman, B. 1959. The Motivation to Work. New

York, NY: Wiley.

Hu, L., and Bentler, P. 1999. "Cutoff criteria for fit indexes in covariance structure analysis:

Conventional criteria versus new alternatives." Structural Equation Modeling: A

Multidisciplinary Journal 6(1): 1-55.

Huff, A. 2005. “Closer Ties.” Commercial Carrier Journal 162 (8):68-71.

Ilies, R., Schwind Wilson, K., and Wagner, D. 2009. “The Spillover of Daily Job Satisfaction onto Employees' Family Lives: The Facilitating Role of Work-Family Integration.” Academy of Management Journal 52 (1):87-102.

Judge, T.A., Bono, E.J., Thoresen, J.C., and Patton, G.K. 2001a. "The Job Satisfaction-Job Performance Relationship: A Qualitative and Quantitative Review.” Psychological Bulletin 127 (3):376-407.

Judge, T.A., Parker, S., Colbert, A.E., Heller, D., and Ilies, R. 2001b. “Job Satisfaction: A Cross-Cultural Review." In Handbook of Industrial, Work and Organizational Psychology, Volume 2: Organizational Psychology, edited by N. Anderson, D.S. Ones, H.K. Sinangil, and C. Viswesvaran, 25-52. London: Sage.

Karasek, R. 1979. “Job Demand, Job Decision Latitude, and Mental Strain: Implications for Job Redesign.” Administrative Science Quarterly 24 (2):285-308.

Karasek, R., and Theorell, T. 1990. Healthy Work: Stress, Productivity, and the Reconstruction of Working Life. New York, NY: Basic Books.

Keller, S.B. 2002. "Driver Relationships with Customers and Driver Turnover: Key Mediate Variables Affecting Driver Performance in the Field.” Journal of Business Logistics 23 (1):39-64. 
Keller, S.B., and Ozment, J. 1999. "Managing Driver Retention: Effects of the Dispatcher." Journal of Business Logistics 20 (2):97-120.

Kosteas, V.D. 2011. “Job Satisfaction and Promotions.” Industrial Relations 50 (1):174-194.

Kübler, A., Distel, S., and Veres-Homm, U. 2015. Logistikbeschäftigung in Deutschland. Nuremberg: Fraunhofer Verlag.

Lawler, E. 1973. "Satisfaction and Behavior.” In Motivation and Work Behavior, edited by R. Steers and L. Porter, 332-345. New York, NY: McGraw-Hill.

Locke, E.A. 1969. “Organizational Behavior and Human Performance.” Organizational Behavior and Human Performance 4 (4):309-336.

Mahanta, M. 2012. "Personal Characteristics and Job Satisfaction as Predictors of Organizational Commitment: An Empirical Investigation.” South Asian Journal of Management 19 (4):46-58.

Mallett, T. 2009. “Happy with Their Lot.” Commercial Motor 209 (5328):20-21.

Maslow, A. 1954. Motivation and Personality. New York, NY: Harper \& Row.

Mayo, E. 1945. The Social Problems of an Industrial Civilization. Boston, MA: Harvard University.

McDonald, R. P. 1985. Factor Analysis and Related Methods. Hillsdale, NJ: Erlbaum.

McElroy, J., Rodriguez, J., and Griffin, G. 1993. "Career Stage, Time Spent on the Road, and Truckload Driver Attitudes.” Transportation Journal 33 (1):5-14.

McGregor, D. 1960. The Human Side of Enterprise. New York, NY: McGraw-Hill.

Mertel, B. 2006. “Arbeitszufriedenheit-Eine empirische Studie zu Diagnose, Erfassung und Modifikation in einem führenden Unternehmen des Automotives." https://opus4.kobv.de/opus4-bamberg/files/90/Diss.Kap.1-12_2006-08-08.pdf, (accessed 02 May 2015). 
Miles, J.N.V., and Shevlin, M.E. 2001. Applying regression and correlation: a guide for students and researchers. London: Sage Publications.

Min, H., and Emam, A. 2003. "Developing the Profiles of Truck Drivers for Their Successful Recruitment and Retention.” International Journal of Physical Distribution \& Logistics Management 33 (2):149-162.

Min, H., and Lambert, T. 2002. “Truck Driver Shortage Revisited.” Transportation Journal $42(2): 5-16$.

Muthén, L.K., and Muthén, B.O. 2012. Mplus User's Guide. Seventh Edition. Los Angeles, CA: Muthén \& Muthén.

Pereira da Silva-Junior, F., Saraiva Nunes de Pinho, R., de Mello, M., Sales de Bruin, V., and de Bruin, F. 2009. "Risk Factors for Depression in Truck Drivers." Social Psychiatry and Psychiatric Epidemiology 44 (2):125-129.

Podsakoff, P.M., MacKenzie, S.B., Lee, J.-Y., and Podsakoff, N.P. 2003. “Common Method Biases in Behavioral Research: A Critical Review of the Literature and Recommended Remedies.” Journal of Applied Psychology 88:879-903.

Podsakoff, P.M., MacKenzie, S.B., and Podsakoff, N.P. 2012. "Sources of Method Bias in Social Science Research and Recommendations on How to Control It.” Annual Review of Psychology 63:539-569.

Podsakoff, P.M., and Organ, D.W. 1986. "Self-reports in Organizational Research: Problems and Prospects.” Journal of Management 12:531.

Porter, L.W., and Lawler, E.E. 1968. "What Job Attitudes Tell About Motivation.” Harvard Business Review 46:118-126.

Revelle, W., and Zinbarg, R. E. 2009. “Coefficients alpha, beta, omega, and the glb Comments on Sijtsma”. Psychometrika 74: 145-154. 
Richard, M., LeMay, S., Taylor, S., and Turner, G. 1994. "An Investigation of the Determinants of Extrinsic Job Satisfaction Among Drivers.” The International Journal of Logistics Management 5 (2):95-106.

Richard, M., LeMay, S., and Thylor, G.S. 1995. “A Factor-Analytic Logit Approach to Truck Driver Turnover.” Journal of Business Logistics 16 (1):281-298.

Ritter, J., and Anker, R. 2002. “Good jobs, bad jobs: Workers' evaluation in five countries." International Labour Review 141 (4):331-358.

Roberts, J. 2014. “What Do Drivers Want?” Commercial Carrier Journal 171 (8):93-98.

Roethlisberger, F., and Dickson, W. 1939. Management and the Worker. Cambridge, MA: Harvard University Press.

Ronan, W.W., and Organt, G.J. 1973. "Determinants of Pay and Pay Satisfaction.” Personnel Psychology 26 (4):503-520.

Saridakis, G., Muñoz Torres, R., and Johnstone, S. 2013. "Do Human Resource Practices Enhance Organizational Commitment in SMEs With Low Employee Satisfaction?” British Journal of Management 24 (3):445-458.

Schneider, B., and Bowen, D. 1993. "The Service Organization: Human Resources Management Is Crucial.” Organizational Dynamics 21 (4):39-52.

Schulz, S.A., Luthans, K.W., and Messersmith, J.G. 2014. "Psychological Capital.” International Journal of Physical Distribution \& Logistics Management 44 (8/9):621-634.

Srivastava, S. 2013. "Job Satisfaction and Organizational Commitment Relationship: Effect of Personality Variables.” Vision 17 (2):159-167.

Statista. 2015. "Bestand an Lkw-Fahrerlaubnissen in Deutschland in den Jahren 2006 bis 2015 (in Millionen)." http://de.statista.com/statistik/daten/studie/200334/umfrage /entwicklung -des-bestandes-an-lkw-fahrerlaubnissen/, (accessed 12 May 2015). 
Stephenson, F.J., and Fox, R.J. 1996. "Driver Retention Solutions: Strategies for For-Hire Truckload (TL) Employee Drivers.” Transportation Journal 35 (4):12-25.

Suzuki, Y. 2007. “Truck Driver Turnover: What Rate Is Good Enough?” International Journal of Physical Distribution \& Logistics Management 37 (8):612-630.

Suzuki, Y., Crum, M., and Pautsch, G. 2009. "Predicting Truck Driver Turnover." Transportation Research Part E: Logistics and Transportation Review 45 (4):538-550.

Tabachnick, B. G., and Fidell, L. S. (2006). "Using Multivariate Statistics, 5th ed.” Boston: Pearson.

Taylor, G.S. 1991. "Using Performance Appraisals of Dispatchers to Reduce Driver Turnover." Transportation Journal 31 (4):49-55.

Tett, R.P., and Meyer, J.P. 1993. "Job satisfaction, Organizational commitment, Turnover intention, and Turnover: Path Analyses based on Meta-analytic Findings.” Personal Psychology 46 (2):259-293.

TÜV. 2012. “Aktuelle Studie: Fahrermangel bei Lkw bedroht auch die Verkehrssicherheit.” TÜV Rheinland.

http://www.tuv.com/news/de/deutschland/ueber_uns/presse/meldungen/newscon tentde_110278.jsp/Aktuelle\%20Studie:\%20Fahrermangel\%20bei\%20Lkw\%20bedroht\%2 0auch\%20die\%20Verkehrssicherheit (accessed: 12.12.13).

Vroom, V. 1964. Work and Motivation. New York, NY: Wiley.

Wagner, S.M., and Kemmerling, R. 2010. "Handling Nonresponse in Logistics Research." Journal of Business Logistics 31:357-381.

Walter, M. 2012. Fahrermangel - Absehbare Katastrophe. Güterverkehr 1(2012):18-20. Williams, Z., Garver, M.S., and Stephen, T.G. 2011. 'Understanding Truck Driver NeedBased Segments: Creating a Strategy for Retention.” Journal of Business Logistics 32 (2):194-208. 
Williamson, A., Bohle, P., and Quinlan, M. 2009. "Short Trips and Long Days - Safety and Health in Short-Haul Trucking." Industrial \& Labor Relations Review 62 (3):415-429. 